\title{
31st Annual Meeting of the Psychonomic Society New Orleans November 16-18, 1990
}

\section{ERRATA AND OTHER CHANGES TO PROGRAM (September 4, 1990)}

New Chair: $\quad$ Language Development session, Regency Ballroom A, Friday morning, 9:5511:50-Cristina Cacciari, Università di Bologna.

Abstract 196: Second author should be added-KAREN ARNELL, University of Calgary.

Abstract 227: Third author added-JACKIE HAYNES, University of Missouri-Kansas City.

Abstract 273: $\quad$ Erratum-The last word in the title should be "Sentences" rather than "Sequences."

Abstract 317: S. Greenberg and A. Koriat paper, "The Missing-Letter Effect in Hebrew: Word Frequency or Word Function?' ' has been moved to Poster Session II (replacing 407).

Abstract 377: A new paper has replaced the original, withdrawn one in the 3-D/Movement Perception II session, Regency Ballroom H, Saturday afternoon:

\section{4:50-5:05}

Spaciotemporal Integration in Object Perception: Some New Phenomena. THOMAS F. SHIPLEY \& PHILIP J. KELLMAN, Swarthmore College-Some new phenomena will be presented in which sequential transformations of spatially separated visible elements lead to perception of moving objects and boundaries spanning the regions between elements. Data will be presented from a series of experiments investigating the limits of spatial and temporal integration processes. We will discuss the possibility that these phenomena illustrate members of a formally similar class of transformations, of which accretion and deletion is one member, which support unit formation.

Abstract 407: $\quad$ P. W. Kerr and G. W. McConkie paper, "Control of Fixation Positions in Words During Reading," has been moved to the Letter/Word Processing session, Burgundy Room, Saturday morning, 11:45-12:00 (replacing 317).

Abstract 556: $\quad$ C. I. Abramson and R. D. Feinman paper, "Studies of Barpress Conditioning in a Crustacean Species," has been moved to the Associative Learning II session, Burgundy Room, Sunday morning, 12:55-1:05. 